\title{
PERKAWINAN BEDA AGAMA PERSPEKTIF HUKUM ISLAM
}

\author{
Fathol Hedi \\ Institut Islam Mamba'ul'Ulum Surakarta \\ e-mail: fatholhedi@gmail.com
}

\begin{abstract}
Abstrak: Terjadinya perbedaan pendapat di kalangan ulama tentang pernikahan beda agama karena perbedaan penafsiran pengertian antara ahli kitab dengan musyrikin. Ada yang menyamakan antara ahli kitab dengan musyrik karena substansi perilaku ahli kitab itu sendiri. Dengan demikian, ketentuan hukum pernikahannya ada yang membolehkan dan ada juga yang mengharamkan. Pendekatan dalam memahami hukum (al-Qur'an), seperti nasikh mansuk, ithlaqul lafdzi dan sadz aldzari'ah, takhsis dan 'am, asbab an-nuzul ayat telah membawa ragam pendapat di kalangan ulama. Pendekatan ithlaqul lafdzi, melihat dari sisi kemutlakan lafadz ayat, sehingga ketika lafadz itu menunjuk kepada term tertentu, maka itulah yang dimaksud hukum oleh ayat tersebut. Pendekatan asbab al-nuzul ayat dalam konteks kebolehan pernikahan muslim dan muslimah dengan musyrik atau non muslim termasuk ahli kitab karena ayat yang turun itu ditujukan kepada kaum musyrik Arab bukan pada yang lainnya. Dengan demikian berlakulah ketentuan hukum khas, yaitu hukum itu berlaku sesuai dengan kekhususan sebab, bukan kepada keumuman lafadz. Artinya pengharaman perkawinan beda agama dengan non muslim tidak berlaku secara umum, hanya yang dituju oleh ayat dimaksud, sehingga menikah dengan non muslim selain bangsa Arab menjadi boleh. Demikian sebaliknya, keharaman itu terjadi karena pemberlakuan hukum 'am dari ayat al-Qur'an, yaitu pelarangan secara umum tentang pernikahan beda agama.
\end{abstract}

Kata kunci: perkawinan beda agama, hukum Islam

\section{PENDAHULUAN}

Perkawinan merupakan sunnatullah untuk mendapatkanketurunan. ${ }^{1}$ Perkawinan yang dilakukan manusia harus berbeda dengan makhluk lainnya. Manusia sebagai makhluk Tuhan diciptakan dalam bentuk yang sempurna ${ }^{2}$ dari segi fisik maupun psikis, sehingga manusia mampu menangkap fenomena rasional dengan akalnya dan fenomena irrasional dengan hati nuraninya. Perkawinan satu-satunya jalan memperoleh keturunan, baik dilakukan sesuai dengan ketentuan hukum agama atau tidak.Islam sebagai agama memandang perkawinan adalah sesuatu yang sakral dan bernilai ibadah, oleh karena itu perkawinan harus dilaksanakan sesuai denganketetapan Allah dalam al-Qur'an dan Sunah Rasul. Perkawinan yang dilakukan sesuai ketetapan tersebut, dikatagorikan sah menurut hukum Islam. ${ }^{3}$ Perkawinan sebagai miistasqan ghalidzan, ${ }^{4}$ idealnya dilakukan pria dengan wanita yang mempunyai kesamaan keyakinan,didasari cinta dan ketulusan hati. Sebab perkawinanakan berimplikasi pada persoalan akhlak, tujuan, visi dan misi yang akan dibangun oleh suatu keluarga sebagai sebuah unit terkecil dari kehidupan masyarakat. Dengan kesamaan dan keterpaduan sebagaimana disebutkan, sebuah keluarga sakinah, mawaddah, warahmah akan

${ }^{1}$ QS.YaaSiin: 36, QS. Al-Hujurat: 13, QS. An-Nisa':1.

${ }^{2}$ QS. Al-Tiin: 4,

${ }^{3}$ SyaikhKamil Muhammad 'Uwaidah, FiqihWanita, (terj.), Jakarta Timur: Pustaka al-Kautsar, 1998, hal 405.

\footnotetext{
${ }^{4}$ Depag RI, Al-Qur'an danTerjemahnya,Semarang:Thoha Putra, 1989, hal. 120.
} 
terwujud. Namun, di sisi lain pluralitas masyarakat tidak dapat dipungkiri, sehingga interaksi antar individu yang berbeda suku, ras, bangsa bahkan agama sering menimbulkan tindakantindakan hukum tertentu, termasuk perkawinan beda agama. Para ulama menanggapi perkawinan beda agama terjadi kontroversi pendapat, sebagian memperbolehkan dan sebagian lain sebaliknya mengharamkan dengan alasan-alasan tertentu. Agar lebih jelas makalah ini akan mendeskripsikannya lebih lanjut.

\section{PEMBAHASAN}

Perkawinan menurut konsep Islam tidak boleh menyimpang dari al-Qur'an dan Hadits, sebab keduanya menjadi sumber pokok semua tindakan hukum. Rumusan perkawinan yang tersebar dalam firman Allah secara filosofis mengandung makna diantaranya, pertama Islam memandang perkawinan sebagai sesuatu yang sakral, karena bermula dari perjanjian khusus yang melibatkan Tuhan. Kedua, perkawinan merupakan cara penghalalan terhadap hubungan antara kedua lawan jenis yang semula diharamkan. Ketiga, perkawinan memiliki dimensi psikologis yang sangat dalam, dengan perkawinan kedua insan suami isteri yang semula asing, kemudian menjadi bersatu. Mereka saling memiliki, menjaga, membutuhkan, saling mencintai dan menyayangi, sehingga terwujud keluarga harmonis. Keempat, perkawinan memiliki dimensi sosiologis, yakni dengan perkawinan seseorang memiliki status baru sebagai anggota masyarakat secara utuh. Kelima, perkawinan sebagai wahana untuk keberlangsungan kehidupan manusia secara sah dan bertanggungjawab, sebab tanpa regenerasi populasi manusia di muka bumi akan punah. Lahirnya anak-anak secara naluri memerlukan pemeliharaan dan perlindungan yang sah, yakni oleh kedua orang tua mereka. Orang tua inilah yang bertanggungjawab atas perkembangan fisik dan psikis anak-anaknya, terutama pada saat mereka sebelum beranjak dewasa. Harapannya dikemudian hari mereka menjadi generasi penerus umat manusia yang berkemampuan membangun dan memakmurkan bumi ini. ${ }^{5}$

Namun di sisi lain, terjadinya perkawinan beda agama memicu perbedaan pendapat di kalangan ulama. ${ }^{6}$ Hukum Perkawinan beda agama banyak mengandung resistensi dalam kehidupan masyarakat. Sebab sejak awal lahirnya Islam terutama pasca Rasul di kalangan shahabat terjadi perbedaan dalam menafsirkan ayat al-Qur'an dan hadits tentang perkawinan antara muslim dengan non muslim. Ada ketidak sepahaman di kalangan mereka, kreteria siapakah yang tergolong musyrik dan ahl kitab. Sebagian mereka menganggap ahli kitab sebagai musyrik, tetapi sebagian lainnya membedakan secara tegas. ${ }^{7}$

Imam al-Razi, menyatakan bahwa orang Kristen dan Yahudi sama dengan musyrik, sebagaimana ketentuan surat at-Taubah: 30, artinya,"orang-orang Yahudi berkata, "Uzair itu putra Allah" dan orang Nasrani berkata, "Al-Masih itu putra Allah". Demikian itulah ucapan mereka dengan mulut mereka, mereka meniru ucapakan orang kafir yang terdahulu, dilaknati Allah-lah mereka, bagaimana mereka sampai berpaling". 8 Demikian pula ayat 31 , artinya, "Mereka menjadikan orang- oang alimnya, dan rahib-rahib mereka sebagai Tuhan

\footnotetext{
${ }^{5}$ M. Karsayuda, Perkawinan Beda Agama: Menakar Nilai-Nilai Keadilan dalam Kompilasi Hukum Islam, Yogyakarta: Total Media, 2006, hal. 66-69.

${ }^{6}$ Abdul Wahab Khalaf, (penyad.), Wajidi Sayadi, Op. Cit. hal. 91.

${ }^{7}$ Muhammad Ali al-Sabuni, TafsirAyat al-Ahkam, Makkah: Dar al-Qur'an, 1972, hal. 536.

${ }^{8}$ Depag. RI, Al-Qur'an dan Terjemahnya, Semarang: Thoha Putra, 1989, hal. 282.
} 
selain Allah, dan mereka mempertuhankan Al-Masih putra Maryam, padahal mereka hanya disuruh menyembah Tuhan Yang Maha Esa, tidak ada Tuhan selain Dia, Maha Suci Allah dari apa yang mereka persekutukan”. Jika demikian adanya, karena ahli kitab baik Yahudi maupun Nasrani disamakan dengan musyrik, maka perkawinan mereka dengan muslim atau muslimahdiharamkan, sebagaimana dijelaskan dalam QS. al-Baqarah: 221, yaitu: Artinya: Janganlah kamu menikah dengan perempuan-perempuan musyrik sebelum mereka beriman. Perempuan budak yang beriman lebih baik dari pada perempuan musyrik sekalipun ia menarik hatimu. Juga janganlah menikahkan (perempuanmu) dengan laki-laki musyrik sebelum mereka beriman. Seorang laki-laki budak beriman lebih baik dari pada seorang lakilaki musyrik sekalipun mereka menarik hatimu. Mereka (kaum musyrik) akan membawa ke dalam api (neraka), sedangkan Allah mengajak ke surga dan ampunan dengan izin-Nya...

Demikian juga surat al-Mumtahanah: 10 yaitu: Artinya: Hai orang-orang yang beriman, apabila datang berhijrah kepadamu perempuan-perempuan yang beriman, maka hendaklah kamu uji (keimanan) mereka. Allah lebih mengetahui tentang keimanan mereka; maka jika kamu telah mengetahui bahwa mereka (benar-benar) beriman maka janganlah kamu kembalikan mereka kepada (suami-suami mereka) orang-orang kafir. Mereka tiada halal bagi orang-orang kafir itu dan orang-orang kafir itu tiada halal pula bagi mereka. Dan berikanlah kepada (suami-suami) mereka mahar yang telah mereka bayar. Dan tiada dosa atasmu mengawini mereka apabila kamu bayar kepada mereka maharnya. Dan janganlah kamu tetap berpegang pada tali (perkawinan) dengan perempuan-perempuan kafir; dan hendaklah kamu minta mahar yang telah kamu bayar; dan hendaklah mereka meminta mahar yang telah mereka bayar. Demikianlah hukum Allah yang ditetapkan-Nya di antara kamu. Dan Allah Maha Mengetahui lagi Maha Bijaksana. Memahami ayat di atas, Imam Muhammad al-Razi menjelaskan bahwa ayat-ayat itu merupakan ayat-ayat permulaan yang secara eksplisit menunjukkan hal-hal yang halal ( $m a$ yuhallu) dan hal-hal yang dilarang ( $m a$ yuhramu). ${ }^{9}$ Dengan demikian, menikahi orang musyrik merupakan salah satu perintah Tuhan dalam kategori haram dan dilarang. disamping itu ayat tersebut, termasuk ayat Madaniyah ${ }^{10}$ yang pertama kali turun dan membawa pesan khusus agar orang muslim tidak menikahi wanita musyrik atau sebaliknya.

Abdullah Ibn Umar berpendapat, termasuk golongan syirik mereka yang menuhankan Isa ibn Maryam dan menuhankan Uzer. Oleh karena itu, wanita ahli kitab dari kalangan Nasrani dan Yahudi termasuk katagori musyrik.Karena mereka termasuk musyrik, maka tidak halal untuk dikawini. ${ }^{11}$ Para ulama mengharamkan secara mutlak perkawinan dengan ahli kitab yang dikatagorikan musyrik, karena mereka menggunakan pendekatan nasikh mansukh dan pendekatan ithlaqullafdhi. Dengan pendekatan nasikh mansukh, ${ }^{12}$ ayat yang menyatakan kebolehan perkawinan beda agama bagi pria muslim terhadap perempuan ahli kitab sebagaimana termaktub dalam QS. al-Maidah: 5 ternasakh (terhapus) oleh ayat yang menyatakan bahwa pria muslim dilarang menikah dengan perempuan musyrik sebagaimana termaktub dalam QS. al-Baqarah: 221. ${ }^{13}$ Begitupun dengan pendekatan ithlaqullafdhi, maka

\footnotetext{
${ }^{9}$ Imam Muhammad al-Razi, Tafsir al-Kabir wa Mafatih al-Ghaib, Beirut: Dar al-Fikr, 1995, hal. 59.

${ }^{10}$ Abdul Djalal HA, Ulumul Qur'an, Surabaya:DuniaIlmu, 2000, hal. 78-86.

${ }^{11}$ Ibn Katsir, Tafsir al-Qur'an al- 'Adhim, Beirut: Da al-Ma'rifah, 1989, hal. 22.

${ }^{12}$ Abdul Djalal HA, Ulumul Qur'an, Surabaya: Duniallmu, 2000, hal. 106-122.

${ }^{13}$ M. Quraish Shihab, Tafsir al-Mishbah Pesan, Kesan dan Keserasian al-Qur'an, Ciputat: Lentera Hati,
} 
kata musyrikiina (pria- pria musyrik) dan musyrikaat (perempuan-perempuan musyrik) diyakini bermakna mutlak, sehingga mencakup seluruh manusia yang menyekutukan Allah. Bagi kelompok ini, seluruh manusia yang beragama selain agama Islam (non muslim) ${ }^{14}$ tergolong musyrik. Sehingga pernikahan dengan siapapun orang di luar Islam hukumnya haram. Sedangkan tinjauan lain dengan pendekatan sadz al-dzari'ah, ${ }^{15}$ jika dikhawatirkan terjadi kemafsadatan, maka mendahulukan nikah dengan kitabiyah hukumnya adalah haram. ${ }^{16}$

Secara substansial, penyamaan ahli kitab dengan musyrik dapat dibenarkan karena perilaku penuhanan terhadap Isa putra Maryam dan Uzair anak Allah oleh para pengikut ahli kitab. Namun, jika dilihat ayat lain dalam al-Qur'an secara jelas antara ahli kitab dan musyrik dibedakan. Misalnya, dalam QS. al-Bayyinah: 1 artinya, "Orang-orang kafir yakni ahli kitab dan orang-orang musyrik (mengatakan bahwa mereka) tidak akan meninggalkan (agamanya) sebelum datang kepada mereka bukti yangnyata". Demikian juga dalam QS. alBaqarah: 105 "Orang-orang kafir dari Ahli Kitab dan orang-orang musyrik tiada menginginkan diturunkannya sesuatu kebaikan kepadamu dari Tuhanmu. Dan Allah menentukan siapa yang dikehendaki-Nya (untuk diberi) rahmat-Nya (kenabian), dan Allah mempunyai karunia yang besar".

Ayat di atas dapat diambil pengertian bahwa penggunaan "wawu 'athaf" adalah bermakna "dan", yang menunjukkan adanya perbedaan antara orang-orang kafir ${ }^{17}$ musyrik dengan ahli kitab, karena dalam kaidah bahasa Arab "huruf athaf" memiliki arti "pembeda" antara kata sebelumnya dengan kata sesudahnya. Oleh karena itu pandangan yang memasukkan non muslim (ahli Kitab) dengan musyrik tidak dapat dibenarkan. Dan al-Qur'an tidak pernah menyebutkan ahli kitab dengan kata musyrik sebagai panggilan bagi mereka. Alasan lain sebagaimana yang diungkap oleh Abu A'la al-Maududi, menyatakan artinya: 'Bukadan bacalah al-Qur'an dari awal, mulai surat al-Fatihah sampai akhir surat al-Nas akan ditemukan istilah-istilah tiga katagori kepercayaan yang memiliki makna berbeda diantara masing-masing ketiganya, seperti term musyrik, ahli kitab dan ahl al-iman. ${ }^{18}$ Dengan alasan pembedaan tersebut, maka sebagian pendapat ulama menyatakan pernikahan antara muslim dengan ahli kitab diperbolehkan. Di kalangan jumhur ulama kebolehan menikahi ahli kitab didasarkan firman Allah QS. al-Maidah: 5, Artinya: Pada hari ini dihalalkan bagimu yang baik-baik. Makanan (sembelihan) orang-orang yang diberi al-Kitab itu halal bagimu, dan makanan kamu halal pula bagi mereka. (Dan dihalalkan mengawini) wanita-wanita yang menjaga kehormatan di antara wanita-wanita yang beriman dan wanita-wanita yang menjaga kehormatan di antara orang- orang yang diberi al-Kitab sebelum kamu, bila kamu telah membayar maskawin mereka dengan maksud menikahinya, tidak dengan maksud berzina dan tidak (pula) menjadikannya gundik-gundik. Barang siapa yang kafir sesudah beriman (tidak menerima hukum-hukum Islam) maka hapuslah amalannya dan ia di hari akhirat termasuk orang-orang merugi.

\footnotetext{
2000, hal. 443.

${ }^{14}$ Al-Jaziri, al-Fiqh 'ala al-Madzahib al-Arba'ah, Beirut: Dar al-ihya' al-Turats al-'Arabi, 1996, hal. 75.

${ }^{15}$ Muhammad Abu Zahrah, Ushul Fiqh, Jakarta: Pustaka Firdaus, 2002, hal. 438-439.

${ }^{16}$ Al-Jaziri, al-Fiqh 'ala al-Madzahib al-Arba'ah, Beirut: Dar al-ihya' al-Turats al- 'Arabi, 1996, hal. 75.

${ }^{17}$ Nurcholish Madjid, dkk, FiqhLintas Agama, Jakarta: Yayasan Paramadina, 2004, hal. 156-157.

${ }^{18}$ Abu A'la al-Maududi, al-Islam fi Mawajahah al-Tahaddiyah al-Mu'assharah, Kuwait: Dar al-Qalm,
} tt., hal. 112. 
Sejarah juga menunjukkan beberapa shahabat Nabi telah menikahi ahli kitab darikalangan wanita Nasrani. ${ }^{19}$ Seperti Usman bin Affan mengawini Nailah binti al-Farafidah al-Kalbiyyah dari kalangan Nasrani yang kemudian memeluk Islam, dan Hudzaifah mengawini wanita ahli kitab dari kalangan Yahudi penduduk kota Madina. ${ }^{20}$ Mengenai kasus perkawinan Hudzaifah, Umar Ibn Khattab pernah memerintahkan agar ia menceraikannya, karena ia khawatir jika jejak Hudzaifah ini akan diikuti oleh orang Islam lainnya, dan mereka lebih memilih mengawini wanita ahli kitab yang cantik dari pada mengawini wanita muslimah. Hal ini menurut Umar Ibn Khattab akan menimbulkan fitnah di kalangan wanita muslimah. $^{21}$

Penafsiran ulama membolehkan menikahi wanita ahli kitab bagi pria muslim karena mereka menggunakan pendekatan takhsis ayat bil ayat, dan pendekatan nasikh mansukh. Ayat al-Qur'an yang melarang pernikahan beda agama kepada perempuan musyrik (QS. alBaqarah: 221), secara umum sebenarnya tidak mencakup perempuan ahli kitab, meskipun mereka dalam keimanannya telah terkontaminasi dengan konsep keimanan yang menjurus kepada kemusyrikan. Alasannya karena dalam ayat lain, QS. al-Maidah: 5, menyatakan kebolehan menikah dengan mereka. Artinya QS. al-Maidah dimaksud memberikan pengkhususan (takhsis), bahwa larangan menikah dengan perempuan musyrik QS. alBaqarah: 221 tidak berlaku terhadap perempuan ahli kitab. ${ }^{22}$ Sedangkan berlakunya ketetapan nasikh mansukh, karena QS. al-Baqarah: 221 lebih dulu turun dari pada QS. al-Maidah: 5, sehingga ayat dalam kasus yang sama yang turun lebih dulu ternasakh oleh ayat yang turun belakangan.

Adapun pendapat yang memperbolehkan perkawinan beda agama bagi laki-laki atau perempuan muslim, baik terhadap ahli kitab atau non ahli kitab, mereka menggunakan pendekatan "al-'ibratu bikhususis sababi la biumumil lafadz (hukum hanya mengikat dan menjangkau sebab yang spesifik dan tidak bisa menjangkau keseluruhan teks yang umum)”, intinyahukum hanya dapat diberlakukan terhadap sebab yang spesifik, tidak untuk teks yang umum. Artinya, QS. al-Baqarah: 221 yang melarang pria muslim menikah dengan perempuan musyrik, begitupun perempuan muslim dengan pria musyrik, tidak bisa diberlakukan secara umum kepada semua perempuan atau pria musyrik. Alasannya jika dikaji dengan pendekatan azbab an-nuzul ${ }^{23}$ ditemukan fakta bahwa sebab spesifik turunnya ayat itu adalah larangan menikah dengan manusia yang berasal dari komunitas musyrik Arab (kaum jahiliyah). Dengan pendekatan kaidah tersebut di atas, maka larangan menikah beda agama hanya berlaku terhadap pria atau perempuan musyrik Arab atau kaum Jahiliyyah, dan tidak berlaku kepada penganut agama lain. ${ }^{24}$ Sehingga, mereka menyimpulkan perkawinan beda agama diperbolehkan dengan penganut agama manapun selama mereka tidak berprilaku seperti kaum musyrik Arab. Kebolehan ini berlaku baik untuk pria muslim maupun untuk

\footnotetext{
${ }^{19}$ Ibn Katsir, Tafsir al-Qur'an al- 'Adhim, Beirut: Da al-Ma'rifah, 1989, hal. 22.

${ }^{20}$ Wahbah al-Zuhaili, al-Fiqh al-Islami wa Adillatu, Damaskus: Dar al-Fikr, 2007,

${ }^{21}$ Ibn Qadamah, al-Mughni, Riyadh: Maktabah al-Riyad al-Haditsah, tt., hal. 590

${ }^{22}$ IbnTaimiyah, Majmu' Fatawa, Riyad: al-Mamlakah al-'Arabiyah al-Sa'udiyah, 1398 H, hal. 178.

${ }^{23}$ Manna Khalilal-Qattan, Mabahis $f i$ 'Ulumil Qur'an, Riyad: Mansyurat al-'Asr al-Hadis, 1973, hal. 110-112

${ }^{24}$ Rasyid Ridha, Tafsir al-Manar, Cairo: Dar al-Manar, 1367 H, hal. 193
} 
perempuan muslim.

Alasan berikutnya, apabila memaknai kata musyrikin dan musyrikaat (QS. alBaqarah: 221) dengan pendekatan ithlaqul lafdzi, maka seharusnya kalau pelarangan itu konsisten, perkawinan dengan penganut Islampun bisa juga ada yang diharamkan, jika salah satu pihak (laki-laki atau perempuan) melakukan tindakan syirik. Karena perilaku syirik dapat menimpa siapapun, termasuk bagi mereka yang memeluk Islam. Demikian pula persoalan lainnya akan sulit mengidentifikasi seorang apakah musyrik atau tidak, dan pertanyaan berikutnya siapa yang memiliki otoritas untuk menentukan kemusyrikan seseorang. Dengan argumen semacam itu, mereka meyakini betul bahwa pelarangan perkawinan dalam QS. al- Baqarah: 221, hanya ditujukan kepada kelompok musyrik Arab saja, atau jika diperluas pengertiannya siapa saja yang memiliki karakter dan perilaku negatif seperti kelompok musyrik Arab.

Sedangkan QS. al-Mumtahanah: 10, yang menyatakan pelarangan perempuan muslim menikah dengan pria non muslim, sesunguhnya yang dimaksud ayat tersebut adalah larangan menikah hanya kepada pria non muslim yang berasal dari komunitas kafir. Dan kelompok non muslim yang tidak boleh dinikahi memenuhi dua kreteria, yaitu kafir dan musyrik, tetapi al-Qur'an membedakan antara kafir, musyrik dan ahli kitab. Disamping itu, dalam al-Qur'an tidak terdapat teks yang tegas dan menyatakan larangan atau kebolehan perempuan untuk menikah dengan ahli kitab, tidak seperti pria muslim yang dalam al-Qur'an dinyatakan dalam QS. al-Maidah: 5, hanya hadits yang dikatagorikan mauquf ${ }^{25}$ menyatakan artinya "Rasulullah saw bersabda: kami menikahi wanita- wanita ahli kitab dan laki-laki ahli kitab tidak boleh menikahi wanita-wanita kami (muslimah). ${ }^{26}$ Dan Umar Ibn Khattab berpesan, "seorang muslim boleh menikahi wanita Nasrani, akan tetapi laki-laki Nasrani tidak boleh menikahi wanita muslimah. ${ }^{27}$

Ketidaktegasan teks al-Qur'andalam mengatur tentang boleh tidaknya perempuan muslim menikah dengan pria non muslim dan hanya diatur dalam hadits mauquf, maka masalah ini menjadi kasus ijtihadi. Oleh karena itu dengan pendekatan kaidah dalam masalah mu'amalah yaitu "al-ashlu fil asyya'i al-ibahah illa ma dalla alaa tahrimihi"(hukum asal dari segala sesuatu dalam persoalam mu'amalah adalah boleh, hingga ditemukan dalil yang mengharamkannya). Dengan demikian perempuan muslim menikah dengan pria non muslim, selain pria musyrik Arab, dimungkinkan kebolehannya. Alasan kebolehan juga, jika merujuk kepada semangat yang dibawa al-Qur'an yaitu, pertama pluralitas agama merupakan sunnatullah yang tidak dapat dihindari. Tuhan menyebut agama-agama samawi dan mereka membawa ajaran amal shalih sebagai orang yang akan bersama-Nya di surga nanti. Bahkan juga secara eksplisit menyebutkan agar perbedaan jenis kelamin dan suku sebagai tanda agar satu dengan yang lainnya saling mengenal. Pernikahan beda agama dapat dijadikan suatu ruang antara penganut agama mengenal lebih dekat, lebih saling memahami satu sama lain.

Kedua, tujuan dari keberlangsungan pernikahan adalah untuk membangun tali kasih sayang. Oleh karena itu pernikahan sangatlah urgen sebagai wahana membangun toleransi dan kesepahaman antara masing-masing pemeluk agama, apalagi di tengah-tengah rentannya

\footnotetext{
${ }^{25}$ Fatchur Rahman, IkhtisarMusthalahul Hadits, Bandung: PT. Al-Ma'arif, 1974, hal. 225.

${ }^{26}$ Ibn Jarir al-Thabari, Jami' al-Bayan al-Ta'wil al-Qur'an, Beirut: Dar al-Fikr, tt., hal. 465.

${ }^{27}$ Ibn Jarir al-Thabari, Jami' al-Bayan al-Ta'wil al-Qur'an, Beirut: Dar al-Fikr, tt., hal. 465.
} 
hubungan antara agama. Bermula dari ikatan tali kasih sayang inilah akan terajut kerukunan dan kedamaian diantara pemeluk agama, sehingga persatuan dan kesatuan bangsa terwujud dengan baik. Ketiga, Islam membawa semangat pembebasan bukan belenggu. Dari tahaptahap yang dilakukan al-Qur'an sejak larangan pernikahan dengan orang musyrik, kemudian membuka jalan bagi pernikahan muslim dengan ahli kitab merupakan sebuah tahapan pembebasan secara evolutif.

\section{KESIMPULAN}

Terjadinya perbedaan pendapat di kalangan ulama tentang pernikahan beda agama karena perbedaan penafsiran pengertian antara ahli kitab dengan musyrikin. Ada yang menyamakan antara ahli kitab dengan musyrik karena substansi perilaku ahli kitab itu sendiri. Dengan demikian, ketentuan hukum pernikahannya ada yang membolehkan dan ada juga yang mengharamkan. Pendekatan dalam memahami hukum (al-Qur'an), seperti nasikh mansuk, ithlaqul lafdzi dan sadz al-dzari'ah, takhsis dan 'am, asbab an-nuzul ayat telah membawa ragam pendapat di kalangan ulama. Pendekatan nasikh mansukh membolehkan pernikahan antara ahli kitab dengan muslim karena QS. al-Baqarah: 221 tentang pelarangan menikah dengan musyrik telah ternasakh oleh QS. al-Maidah: 5 yang membolehkan menikahi ahli kitab. QS. al-Baqarah: 221 turunnya lebih dulu dari pada QS. al-Maidah: 5, sehingga ayat yang datang sebelumnya ternasakh oleh ayat yang datang kemudian. Pendekatan ithlaqul lafdzi, melihat dari sisi kemutlakan lafadz ayat, sehingga ketika lafadz itu menunjuk kepada term tertentu, maka itulah yang dimaksud hukum oleh ayat tersebut. Pemahaman ini akan membawa kepada pola pemikiran tekstualis, hukum seakan menjadi rigit dan kaku, karena tanpa melihat konteks bagaimana ayat itu turun. Berbeda dengan pendekatan sadz al-dzari'ah, melihat hukum perkawinan beda agama dari kasus maslahat dan mafsadatnya. Apabila perkawinan dimaksud membawa mafsadat lebih besar dari pada maslahatnya, maka perkawinan beda agama itu haram hukumnya, dan demikian pula sebaliknya. Pendekatan asbab al-nuzul ayat dalam konteks kebolehan pernikahan muslim dan muslimah dengan musyrik atau non muslim termasuk ahli kitab karena ayat yang turun itu ditujukan kepada kaum musyrik Arab bukan pada yang lainnya. Dengan demikian berlakulah ketentuan hukum khas, yaitu hukum itu berlaku sesuai dengan kekhususan sebab, bukan kepada keumuman lafadz. Artinya pengharaman perkawinan beda agama dengan non muslim tidak berlaku secara umum, hanya yang dituju oleh ayat dimaksud, sehingga menikah dengan non muslim selain bangsa Arab menjadi boleh. Demikian sebaliknya, keharaman itu terjadi karena pemberlakuan hukum 'am dari ayat al-Qur'an, yaitu pelarangan secara umum tentang pernikahan beda agama.

\section{DAFTAR PUSTAKA}

Abdul Ghafur Anshori, Hukum Perkawinan Islam Perspektif Fikih dan Hukum Positif, Yogyakarta: UII Press, 2011.

Abdul Wahhab Khalaf, 'Ilmu Ushul Fiqh, Cairo: Dar al-Qalm, 1978. , (penyad.), Wajidi Sayadi, Sejarah Pembentukan dan Perkembangan Hukum Islam, Jakarta: Raja GrafindoPersada, 2002. 
Abdul Djalal HA, Ulumul Qur'an, Surabaya: Dunia Ilmu, 2000.

Abu A'la al-Maududi, al-Islam fi Mawajahah al-Tahaddiyah al-Mu'assharah, Kuwait: Dar al-Qalm, tt.

Al-Jaziri, al-Fiqh 'ala al-Madzahib al-Arba'ah, Beirut: Dar al-ihya' al-Turats al-'Arabi, 1996.

Ahmad Warson Munawwir, Al-Munawwir Kamus Arab Indonesia, Yogyakarta: AlMunawwir Press, 1991.

Depag. RI., Al-Qur'an dan Terjemahnya, Semarang: Thoha Putra, 1989

Fatchur Rahman, Ikhtisar Musthalahul Hadits, Bandung: PT. Al-Ma'arif, 1974.

Fathurrahman Djamil, Filsafat Hukum Islam, Jakarta: Logos, 1999.

Hasbi Ash-Shiddiqie, Ilmu-Ilmu Al-Qur'an Media-Media Pokok dalam Menafsirkan alQur'an, Jakarta: Bulan Bintang, 1972.

Rizki Putra, 2000.

Imam Muhammad al-Razi, Tafsir al-Kabir wa Mafatih al-Ghaib, Beirut: Daral-Fikr, 1995.

Tafsir al-Fakhr al-Razi, Mesir: Dar al-Qalam, tt.

Ibn Katsir, Tafsir al-Qur'an al- 'Adhim, Beirut: Dar al-Ma'rifah, 1989.

Ibn Jarir al-Thabari, Jami' al-Bayan al-Ta'wil al-Qur'an, Beirut: Dar al-Fikr,tt.

Ibn Qadamah, al-Mughni, Riyadh: Maktabah al-Riyad al-Haditsah, tt.

Ibn Taimiyah, Majmu’ Fatawa, Riyadh: al-Mamlahah al-'Arabiyah al-Sa'udiyah, 1398 H.

Muhammad Abu Zahrah, Ushul Fiqh, Jakarta: Pustaka Firdaus, 1994.

Muhammad Khalid Mas'ud, Hukum Islam dan Perubahan Sosial, alih bahasa Yudian W. Asmin, Cet. 1, Surabaya: al-Ikhlas, 1995.

Mahmud Syaltut, al-Islam Aqidah wa Syari'ah, ttp.,:Dar al-Qalm, 1966.

, al-Fatawa, Cairo: Dar al-Kalam, tt.

M. Karsayuda, Perkawinan Beda Agama: Menakar Nilai-Nilai Keadilan dalam Kompilasi Hukum Islam, Yogyakarta: Total Media, 2006

Muhammad Ali al-Sabuni, TafsirAyat al-Ahkam, Makkah: Dar al-Qur'an,1972.

Muhammad Amin, Ijtihad Ibn Taimiyah dalam Bidang Figh Islam, Jakarta: INIS, 1991. 
191 Mamba'ul 'Ulum, Vol. 15, No. 2, Oktober 2019: 183-191

M. Quraish Shihab, Tafsir Al-Mishbah Pesan, Kesan dan Keserasian Al-Qur'an, Ciputat: Lentera Hati, 2000.

Muhammad Abu Zahrah, Ushul Fiqh, Jakarta: Pustaka Firdaus, 2002.

Manna Khalil al-Qattan, Mabahis fi 'Ulumil Qur'an, Riyadh: Mansyurat al-'Asr al-Hadis, 1973.

Nurcholish Madjid, dkk., Fiqh Lintas Agama, Jakarta: Yayasan Paramadina,2004.

Rasyid Ridha, Tafsir al-Manar, Cairo: Dar al-Manar, 1367 H.

Syaikh Kamil Muhammad 'Uwaidah,Fiqih Wanita, (terj.), Jakarta Timur: Pustaka al-Kautsar, 1998

Sulaiman Rasyid, Fiqh Islam, Bandung:Sinar Baru, 2009.

Wahbah al-Zuhaili, al-Fiqh al-Islamiwa Adillatu, Damaskus: Dar al-Fikr,2007.

Yusuf Musa, Tarikh al-Fiqh al-Islami, Mesir: Dar al-Kitab al-‘Arabi, 1958. 